\title{
Predatory journals and dubious publishers: how to avoid being their prey
}

\section{Steve Kisely}

\begin{abstract}
SUMMARY
Open access publishing has a dark side, the predatory publishers and journals that exist for revenue rather than scholarly activity. This article helps researchers to: (1) identify some of the commonly used tactics and characteristics of predatory publishing; and (2) avoid falling prey to them. In summary, authors should choose the journal for submission themselves and never respond to unsolicited emails. It is also important to check blacklists such as 'Stop Predatory Journals' and whitelists such the Directory of Open Access Journals.
\end{abstract}

\section{LEARNING OBJECTIVES}

After reading this article, readers should be able to do the following:

- be aware of the dangers of predatory journals and publishers

- use blacklists of predatory journals and publishers' whitelists of legitimate open access journals

- be aware of warning signs that might suggest a predatory journal or publisher.

\section{DECLARATION OF INTEREST}

S.K. is on the editorial board of BJPsych International. He also receives five to ten spam emails a day from predatory journals and publishers.

\section{Key words}

Predatory; journalology; biomedical journal; publishing models; open access.

Open access journals have transformed academic publishing in the past two decades. Journals were previously only available in print form and were supported by library and individual subscriptions and/ or provided as part of the benefits of membership of bodies such as the Royal College of Psychiatrists. There are now several online options for access, including platinum, gold, green and hybrid open access (Flinders University Library 2018).

Platinum open access refers to publications that are free to both authors and readers. These publications are usually supported by a society, institution or government agency so that the contents are freely available. One example is Health Promotion and Chronic Disease Prevention in Canada: Research, Policy and Practice (the HPCDP Journal). This is a monthly, online scientific journal published by the Health Promotion and Chronic Disease Prevention Branch of the Public Health Agency of Canada. Another is BJPsych International (published by Cambridge University Press on behalf of the Royal College of Psychiatrists), given that it is both open access and does not charge authors.

In gold open access, publications are free to read by anyone with internet access, and the costs are usually borne by the authors, their institution or funding body through article processing charges (APCs). An example is BJPsych Open (another CUP/ RCPsych journal). However, sometimes an external organisation will sponsor all, or part, of an issue.

In green open access, authors can archive pre- or post-print versions of their articles in an institutional repository or other online site. The pre-print version is the manuscript that was originally submitted to the journal, the post-print is the final accepted version after responding to reviewers' comments. The authors do not pay APCs but generally cannot use the publisher's formatted version, and there may be an embargo of several months to a year before repository archiving is allowed. The exact conditions are usually spelled out in the copyright agreement between the authors and publisher.

In hybrid open access, subscription journals offer open access to articles on payment of a fee by the author, the author's organisation or the research funder. This is in addition to access by subscription. An example is the CUP/RCPsych journal British Journal of Psychiatry (BJPsych).

However, open access publishing has a dark side, the predatory publishers and journals that exist for revenue rather than scholarly activity.

\section{History}

The term 'predatory journal' was coined by Jeffrey Beall from the University of Colorado to describe
Steve Kisely MD, PhD, DMedRes, FRANZCP, FRCPsych, FFPH, FAFPHM, FAChAM, DFCPA, is a Professor of Psychiatry in the School of Medicine at the University of Queensland in Australia and Adjunct Professor of Psychiatry, Community Health and Epidemiology at Dalhousie University in Canada. He is a psychiatrist and public health physician.

Correspondence: Steve Kisely, School of Medicine, University of Queensland, Level 4, Building 1 , Princess Alexandra Hospital, Ipswich Road, Woolloongabba, OLD 4102, Australia. Email: s.kisely@uq.edu.au

\section{Copyright and usage}

(C) The Royal College of Psychiatrists 2018 


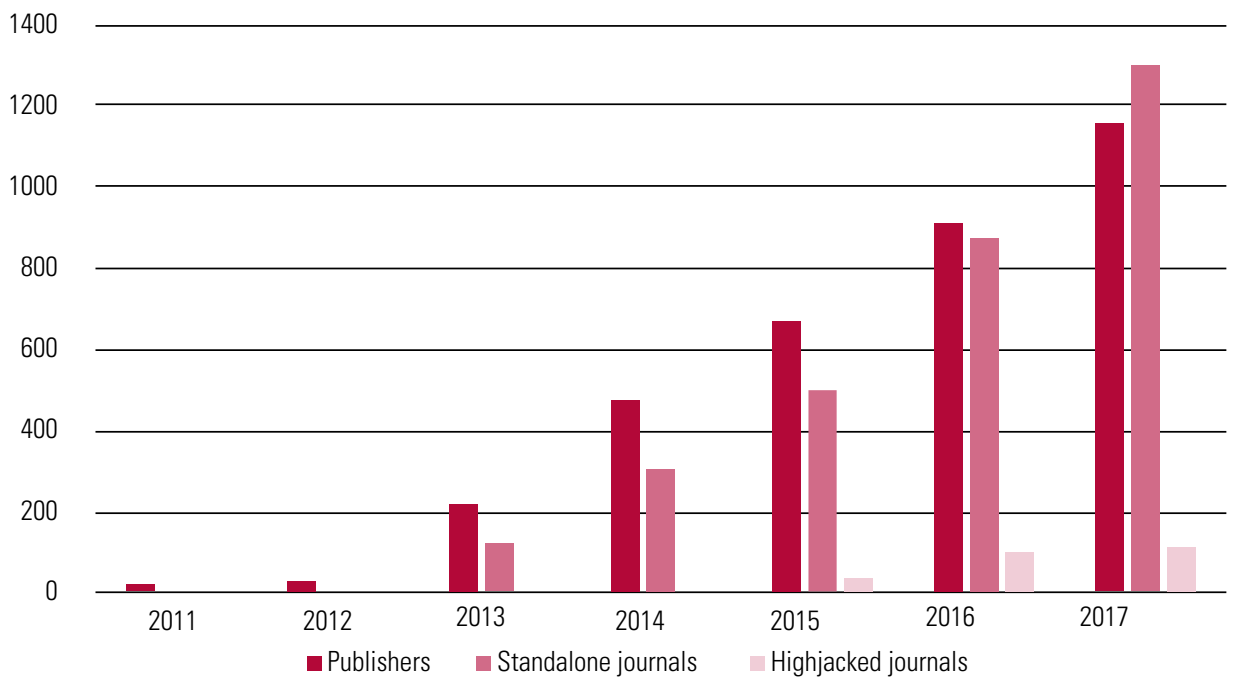

FIG 1 The increase in predatory journals and publishers between 2011 and 2017.

Sources: https://www.timeshighereducation.com/news/infographic-journals-and-publishers-setting-sights-on-theunwary; Manca 2017a,b; Laine 2017; https://predatoryjournals.com/about/.

titles that existed solely to generate income from authors without regard for peer-review or quality (Beall 2012; Laine 2017). These publications shared certain characteristics in terms of their editorial boards, management model and journal integrity. Examples included an absent editor or editorial board, one with insufficient qualifications or the same board across multiple publications. Another was a lack of transparency in author fees, or a name or address (most commonly, North American) that did not adequately reflect the journal's origin. A further indicator was the use of spam email to solicit contributions; these often contained misleading information about citation indices.

Beall provided 'blacklists' of both standalone predatory journals and publishers of multiple titles (Laine 2017). The criteria he used in compiling the list were based on the Code of Conduct for Journal Publishers and the Principles of Transparency and Best Practice in Scholarly Publishing. He later added information on counterfeit impact factors and 'hijacked journals', where predatory publishers created a counterfeit website of a legitimate journal to trick authors into submitting manuscripts (Laine 2017). Over 6 years, Beall's list of all three categories grew steadily (standalone predatory journals, their publishers and hijacked titles) (Fig. 1). For example, the number of predatory publishers increased from just 18 in 2011 (Manca 2017a,b) to 1294 in early 2017, when the website was taken down (Laine 2017). However, several replacement websites either mirror or update the original list (Box 1). The full set of Beall's criteria is also available (Laine 2017).
There have been criticisms of Beall's approach, including a reliance on the opinion of one person (Richtig 2018). It was also unclear whether his criteria distinguished predatory publishing from inexperienced publishers or publishers from low- and middle-income countries (LMICs) (Manca 2017a, b; Richtig 2018). In addition, some features he thought were indicative of predatory journals, such as not being listed in standard databases and the lack of gender or geographical diversity among the editorial board, are genuine problems that can be faced by legitimate titles from LMICs (Laine 2017). Nevertheless, this was the first systematic attempt to identify and address the issue.

An alternative approach is a 'whitelist' of open access journals that adhere to minimum standards. One example is the Directory of Open Access Journals (DOAJ) (Laine 2017). Publishers that apply for inclusion in the directory must not charge readers or their institutions for access and must exercise peer-review or editorial quality control. The DOAJ has been criticised for relatively lax standards in the past but has tightened the criteria for inclusion and now awards the DOAJ seal of approval (Box 2) to journals that meet best practice in terms of openness and publishing standards (Van Noorden 2014). This approach has reaped dividends. In one study of neurology and neuroscience journals, only 1 of the 101 predatory neurology titles appeared in the DOAJ (Manca 2017a). There were no predatory journals among the 87 neuroscience titles in the directory. By contrast, inclusion in PubMed is a relatively poor indicator of quality (Manca 2017c). In the same study of neurology 
BOX 1 Online sources of information on predatory journals

- Beall's list of predatory publishers: https://clinicallibrarian.wordpress.com/2017/01/23/bealls-list-of-predatorypublishers/; https://beallslist.weebly.com/

- The Directory of Open Access Journals (DOAJ): https:// doaj.org/

- Think. Check. Submit.: https://thinkchecksubmit.org/

- Stop Predatory Journals: https://predatoryjournals.com/ about/

BOX 2 Criteria for receipt of the Seal of Approval for Open Access Journals (the DOAJ seal)

To receive the DOAJ seal, journals must meet all of the following criteria:

- provide permanent identifiers (e.g. DOIs) in the papers published

- provide the DOAJ with article metadata

- deposit content with a long-term digital preservation or archiving programme

- embed machine-readable CC licensing information in articles

- allow generous reuse and mixing of content, in accordance with a Creative Commons (CC BY) licence such as CC BY-NC (Non-Commercial), CC BY-SA (Share Alike) or CC BY-ND (Non-Derivative - i.e. the work cannot be amended even for non-commercial purposes)

- have a deposit policy registered with a deposit policy registry

- allow the author to hold the copyright without restrictions

(https://doaj.org/publishers\#seal -accessed 4 October 2018)

journals, $24.7 \%$ of the predatory journals were included in the PubMed database. There were similar findings in a study of rehabilitation medicine, where only 1 out of 59 predatory journals was included in the DOAJ, as opposed to 7 (11.9\%) in PubMed (Manca 2017a,b).

A further website (Cabell's) provides both whiteand backlists. Unfortunately, this is behind a paywall, although some institutions may have a subscription.

A final approach is the use of checklists such as those on the 'Think. Check. Submit.' website (Box 1).

None of these strategies is fool-proof and the World Association of Medical Editors recommends a combination of all three (Laine 2017).

\section{The current situation}

There have been several reviews on the extent and characteristics of predatory publishing in neurology, neuroscience, rehabilitation and emergency medicine (Hansoti 2016; Manca 2017a,b). These papers identified several common themes. For instance, in many cases, it was impossible to determine the geographical location of the journal (Manca 2017a,b). Where it was possible to know, India was the most common country of origin of predatory journals covering neuroscience (39.2\%), followed by the USA (35.5\%) (Manca 2017a). In the case of rehabilitation medicine, most publishers were again based in India (36\%), with the USA in second place (25\%) (Manca 2017b). These figures are consistent with findings from another study, in which 75\% of predatory journals came from LMIC countries (Shamseer 2017).

Article processing charges (in US\$) were generally around $\$ 500-700$, lower than those for journals listed in the DOAJ (approximately \$1000) and for hybrid journals (\$3000) (Manca 2017a,b). The disparity in APCs was even greater in another paper that directly compared predatory and non-predatory journals. This reported a median fee of only $\$ 100$ (interquartile range IQR \$63-150) in predatory journals $(n=59)$ ), $\$ 1866$ (IQR $\$ 800-2205$ ) in open access journals $(n=70)$ and $\$ 3000$ (IQR $\$ 2500-3000)$ in hybrid journals $(n=44)$ (Shamseer 2017).

The same paper noted that predatory journals were more likely to have websites showing spelling errors or poor-quality images than those of legitimate open access or subscription titles. One-third promoted a questionable impact factor, the Index Copernicus Value rather than a recognised index. Other characteristics from Beall's list were less discriminating. For instance, although $73 \%$ of predatory journals did not name an editor or editorial board, $13 \%$ of legitimate journals did not identify an editor-in-chief either (Shamseer 2017).

\section{The risks of predatory journals}

Inexperienced researchers are at particular risk of submitting a paper following an unsolicited email. Although low APCs and fast, guaranteed acceptance may seem tempting, there are serious drawbacks to submitting to a predatory journal. Fees may be hidden and, following so-called publication, papers may not be indexed in a reputable database and so will be difficult to find. Common claims that a title is indexed in Google Scholar are misleading because this is an internet search engine, not an indexing database of pre-selected journals (Shamseer 2017). As predatory journals rarely curate material, there is also the risk that a paper could disappear from one day to the next. 
Potentially legitimate findings may therefore be lost forever, with implications for future systematic reviews. Once made, the mistake to submit to a predatory journal is difficult to correct. This is because predatory journals are very reluctant to retract a published paper, thereby removing the opportunity to submit somewhere more appropriate.

Unfortunately, some researchers submit to predatory journals in full knowledge of their actions because of academic and time pressures - indeed, it has been suggested that predatory journals might be better named pseudo-journals, as some authors are not 'prey' (Laine 2017). This rather short-sighted approach has risks, given that academic promotion and tenure committees are increasingly aware of the problem.

Aside from the potential loss of legitimate research that is published in predatory journals, a lack of peer review and the need to generate revenue can lead to the publication of pseudo-science. Some examples are easy to spot, such as an article on the technological and management qualities of a prehistoric super race living on Mars published in the American Journal of Industrial and Business Management (Arulmani 2013). The following quotation (shown here as it appears online) comes from the abstract:

\begin{abstract}
'The human population lived in MARS planet in prehistoric time shall be called as SUPER MANAGERS with super wisdom. They were considered as great astronomers and experts in management of various planets and in the space in overcoming the prehistoric severe climate conditions occurred due to misalignment of planets. They had only three fundamental principles of management called AKKIE PRINCIPLES or AKKIE CODE.'
\end{abstract}

The lack of peer review has also allowed the publication of spoof science, including a paper based on a Star Trek: Voyager episode submitted from the Starfleet Academy that was published in identical forms in two journals (Paris 2017a,b). A third unlikely publication consisted entirely of one expletive phrase repeated throughout the abstract and text of the paper that was accepted unaltered by the International Journal of Advanced Computer Technology (Stromberg 2014).

Of even greater concern is that predatory journals can give room and credibility to untested controversial ideas that would not normally pass peer review (Richtig 2018). A further danger is that such content will be cited and repeated in other journals, including legitimate titles (Richtig 2018). There may even be threats to patient safety if clinicians apply findings to patient care (Richtig 2018). Although not published in a non-predatory journal, the paper by Wakefield (1998) linking vaccination to autism, which was subsequently retracted (Lancet 2010), is a cautionary tale of how this might happen.

\section{Top tips to avoid being prey}

The World Association of Medical Editors (WAME) recommends a three-step process to avoid predatory journals and publishers (Laine 2017). The first is to assess whether the journal has any of the characteristics Beall viewed as potentially problematic (Laine 2017) or appears in blacklists that update and build on Beall's original work (Box 1). A checklist such as 'Think. Check. Submit.' also helps (Box 3), given concerns that Beall may have been over-inclusive and that some of his criteria may not accurately discriminate between predatory and non-predatory journals (Laine 2017; Richtig 2018). The next is to check whether the journal is listed in the DOAJ or meets DOAJ seal criteria (Box 2). Finally, the journal's website, practices and policies should be reviewed for potential red flags (Box 4) (Moher 2015; Laine 2017; Manca 2017a,b; Shamseer 2017; Richtig 2018). These include a broad scope of content and invitations to contribute or join an editorial board by poorly spelled emailed spam. Authors should be particularly wary of cited impact factors. Predatory journals can either misrepresent their score on recognised impact factor indicators such as Clarivate Analytics' Journal Citation Reports (JCR) and the SCImago Journal Rank (SJR), or use unrecognised alternatives with similar sounding names (Box 4) (Jalalian 2013, 2015; Shamseer 2017).

Do not submit a paper to a journal in response to spam emails ((Fig. 2). Unsubscribing is often difficult, especially in the absence of a relevant link. Replying directly carries the risk of confirming the validity of the email address to which it was sent. Using spam filters may sometimes work but a better strategy is to ask your employer's information technology (IT) department to add the publisher's URL to the institutional firewall blacklist (Moher 2015).

\section{The future}

This important issue merits comprehensive and urgent action to minimise the harms of predatory publishing. Inexperienced researchers would benefit from both mentoring by their supervisor and didactic courses from their institution to increase awareness of the associated dangers. Such courses should form part of the syllabus of any higher degree research. Articles such as this can also help. Importantly, as previously mentioned, researchers should ignore spam email, as attempts to unsubscribe may be futile. Databases such as PubMed and PubMed Central should both enforce and tighten their inclusion criteria for journals, as 


\section{BOX 3 Checklist for your chosen journal}

- Do you or your colleagues know the journal?

- Have you read any articles in the journal before?

- Is it easy to discover the latest papers in the journal?

- Can you easily identify and contact the publisher?

- Is the publisher's name clearly displayed on the journal website?

- Can you contact the publisher by telephone, email and post?

- Is the journal clear about the type of peer review it uses?

- Are articles indexed in services that you use?

- Is it clear what fees will be charged?

- Does the journal site explain what these fees are for and when they will be charged?

- Do you recognise the editorial board?

- Have you heard of the editorial board members?

- Do editorial board members mention the journal on their own websites?

- Is the publisher a member of a recognised industry initiative?

- Do they belong to the Committee on Publication Ethics (COPE)?

- If the journal is open access, is it listed in the Directory of Open Access Journals (DOAJ)?

- If the journal is open access, does the publisher belong to the Open Access Scholarly Publishers Association (OASPA)?

- Is the journal hosted on one of the International Network for the Availability of Scientific Publications' (INASP's) Journals Online platforms (https://www.inasp.info/project/journals-online-project - for journals published in Bangladesh, El Salvador, Honduras, Mongolia, Nepal, Nicaragua, Philippines, Sri Lanka, Vietnam) or on African Journals Online (AJOL: https://www.ajol.info)?

- Is the publisher a member of another trade association?

(http://thinkchecksubmit.org/check - accessed 4 October 2018)

well as monitor the titles that are already included (Manca 2017c, 2018).

Scopus, MEDLINE and the DOAJ already apply higher standards, with the result that in one study of predatory journals in neurology and neuroscience, none of the target journals appeared in Scopus or MEDLINE (Manca 2017a). Researchers and non-predatory journals should also avoid citing articles published in predatory journals (Manca 2017b).

Editors of legitimate journals could also help reduce predatory spam by restricting contact
BOX 4 Red flags suggestive of a predatory journal

- The journal's scope is very broad (e.g. the whole of medicine plus/minus non-biomedical subjects).

- The website contains spelling and grammatical errors, along with poor-quality images.

- The use of unrecognised or misrepresented impact factors, including promotion of the Index Copernicus, CiteFactor, Journal Impact Factor (JIF), Universal Impact Factor (UIF) or Global Impact Factor (GIF).

- Spam emails inviting the submission of papers, or appointment to an editorial board, that are formulaic, ungrammatical and badly spelled (Fig. 2). Suggested topics have little relevance to the recipient's previous work. Content includes flattering salutations, claims of open access, no mention of peer-review, or the possibility of expedited review. There may be no unsubscribe link.

- Instructions for authors do not recommend the use of reporting guidelines such as CONSORT.

- Submissions are sent by email rather than through a manuscript management system.

- The promise of rapid publication.

- There is no information on whether and how content will be digitally preserved.

- Information on article processing charges (APCs) is either missing or misleading, or charges are very low (e.g. less than US\$150).

- Retention of copyright by the publisher/journal even though the journal is supposedly open access. (Moher 2015; Laine 2017; Manca 2017a; Shamseer 2017; Richtig 2018)

details in published papers to the authors' department and university affiliations, omitting email addresses. The latter are usually available on the websites of the authors' host institutions but finding them is more time-consuming. This would eliminate one easy way of obtaining email addresses for predatory spam. In the absence of a uniform change of policy, authors can request that email addresses are withheld.

Predatory journals are also a symptom of wider issues. One is the pressure to publish and an overemphasis on the quantity rather than the quality of publications. Another is the reliance of gold open access on APCs levied on authors. APCs disadvantage junior authors, who may not have access to sufficient funds, as well as those from LMICs who have to apply for discounts based on the gross national income (GNI) or human development index (HDI) of their country (Research4Life 2018). Some journals, such as BJPsych Open, do have funds to assist authors (e.g. the Academic Freedom Fund) 
MCO answers

1 a 2 e 3 e 4 a 5 e

Steve Kisely

$\begin{array}{ll}\text { From: } & \begin{array}{l}\text { Journal of } \\ <\text { Psychiatry@ } \\ \end{array} \\ \text { Sent: } & \text { 27/2/2017 } \\ \text { To: } & \text { Steve Kisely } \\ \text { Subject: } & \text { Artical contribution for "Bipolar disordes" }\end{array}$

Dear Dr. Steve Kisely,

Greetings for your successful life!

We wish you a wealthy, Peaceful for this year 2018.

is established with a sole motive to disseminate knowledge, bring awareness and provide a good quality literature to the developing world and enhance the expertise among the scientific community. We as an Open Access publisher are proving our best abilities in the provision of Science, Technology and Medicine's. As Open Access Publishing allows us to reach millions of readers and give them access to scientific publications.

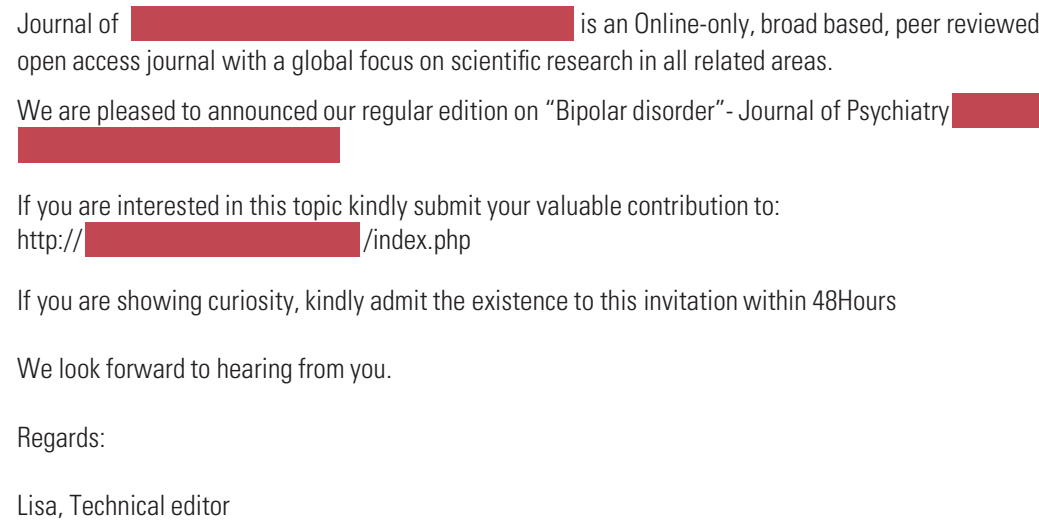

FIG 2 An example of a spam email inviting submission of papers.

but these are discretionary (Kaufman 2018). Green open access may offer a more cost-effective alternative for the dissemination of findings, provided that the copyright agreement is respected. If APCs are levied, there should be greater transparency regarding the amount, given that charges for non-predatory journals range from $\$ 800$ to $\$ 3000$ (Shamseer 2017). These prices help feed the demand for predatory publishing.

\section{Conclusions}

Predatory journals are a threat to the reputation of researchers and their institutions, as well as to scientific knowledge and healthcare delivery. These publications require a multipronged response on the part of researchers, supervisors, institutions, funding bodies and academic publishers. Education and mentoring of researchers are essential, especially those who are at the beginning of their careers. In addition, a greater awareness of the differences between green, platinum and non-predatory gold open access, along with more transparent APCs, would go a long way in undermining the business model for predatory journals.

\section{References}

Arulmani M, Latha VRH (2013) Three principles of Akkie management. American Journal of Industrial and Business Management, 3: 453-65.

Beall J (2012) Predatory publishers are corrupting open access. Nature, 489: 179.

Flinders University Library (2018) Open scholarship (http://flinders. libguides.com/openscholarship/newpublishing). Accessed 4 October 2018.

Hansoti B, Langdorf MI, Murphy LS (2016) Discriminating between legitimate and predatory open access journals: report from the International Federation for Emergency Medicine Research Committee. Western Journal of Emergency Medicine, 17: 497-507.

Jalalian M, Mahboobi H (2013) New corruption detected: bogus impact factors compiled by fake organizations. Electronic Physician, 5: 685-6.

Jalalian M (2015) The story of fake impact factor companies and how we detected them. Electronic Physician, 7: 1069-72.

Kaufman KR (2018) BJPsych Open editorial transition: opportunity, challenge and vision. BJPsych Open, 4: 29-30.

Laine C, Winker MA (2017) Identifying predatory or pseudo-journals. Biochemia Medica, 27: 285-91. 
Lancet (2010) Retraction - Ileal-lymphoid-nodular hyperplasia, non-specific colitis, and pervasive developmental disorder in children. Lancet, 375: 445.

Manca A, Martinez G, Cugusi L, et al (2017a) The surge of predatory openaccess in neurosciences and neurology. Neuroscience, 353: 166-73.

Manca A, Martinez G, Cugusi L, et al (2017b) Predatory open access in rehabilitation. Archives of Physical Medicine and Rehabilitation, 98: 1051-6.

Manca A, Cugusi L, Dvir Z, et al (2017c) PubMed should raise the bar for journal inclusion. Lancet, 390: 734-5.

Manca A, Moher D, Cugusi L, et al (2018) How predatory journals leak into PubMed. Canadian Medical Association Journal, 190: E1042-5.

Moher D, Srivastava A (2015) You are invited to submit.... BMC Medicine, 13: 180.

Paris T, Kim H, Torres B, et al (2017a) Rapid genetic and developmental morphological change following extreme celerity. American Research Journal of Biosciences, 3: 1-3.
Paris T, Kim H, Torres B, et al (2017b) Rapid genetic and developmental morphological change following extreme celerity. Austin Journal of Pharmacology and Therapeutics, 5: 1099.

Research4Life (2018) Eligibility criteria (https://www.research4life.org/ access/criteria/). Accessed 4 October 2018.

Richtig G, Berger M, Lange-Asschenfeldt B, et al (2018) Problems and challenges of predatory journals. Journal of the European Academy of Dermatology and Venereology, 32: 1441-9.

Shamseer L, Moher D, Maduekwe 0, et al (2017) Potential predatory and legitimate biomedical journals: can you tell the difference? A cross-sectional comparison. BMC medicine, 15: 28.

Stromberg J (2014) 'Get me off your fucking mailing list' is an actual science paper accepted by a journal. Vox, 21 Nov.

Van Noorden R (2014) Open access website gets tough. Nature, 512: 17.

Wakefield AJ, Murch SH, Anthony A, et al (1998) Ileal-lymphoid-nodular hyperplasia, non-specific colitis, and pervasive developmental disorder in children. Lancet, 351: 637-41.

\section{MCOs}

Select the single best option for each question stem

1 Which of the following is a credible impact factor indicator?

a Journal Citation Reports (JCR)

b Index Copernicus

c CiteFactor

d Universal Impact Factor (UIF)

e Global Impact Factor (GIF).

2 Which of the following is not a good indicator of whether a journal is predatory?

a Listing in the Directory of Open Access Journals (DOAJ)

b Listing in SCOPUS

c Listing in MEDLINE

d The award of a DOAJ seal

e Listing in PubMed.

\section{Who bears the costs of platinum open} access?

a The subscriber or purchasing library

b The author

c The general public

d Funding agencies

e The journal's publisher.

4 Which of the following is not a useful sign of a predatory journal?

a Lack of gender or geographical diversity in the editorial board

b Submissions are sent by email rather than through a manuscript management system

c Low article processing charges

d Retention of copyright by the publisher/journal even though the journal is supposedly open access

e The journal's scope is very broad.
5 Whom does predatory publishing not harm?

a The author

b The research community

c Funding agencies

d The general public

e The publisher. 